\title{
The Impact of HIV and Plasmodium falciparum Genetic Diversity on Anaemia in HIV-patients Attending Care and Treatment Centre at Baptist Hospital Mutengene
}

\author{
Emmaculate Lum ${ }^{1,2}$, Elias Fomunyam Onyoh ${ }^{3,4}$, Godlove Bunda Wempnje ${ }^{1}$, \\ Bate Agbor Ayukenchengamba ${ }^{1}$, Conica Mfetngwie Njabi ${ }^{1}$, Pascal Obong Bessong ${ }^{6}$ \\ ${ }^{1}$ Department of Zoology and Animal Physiology, Faculty of Science, University of Buea, P.O. BOX \\ 63, Buea, S.W.R., Cameroon. \\ ${ }^{2}$ Department of Biological Sciences, Higher Teachers' Training College, University of Yaounde 1, \\ P.O. BOX 47, Central Region, Cameroon. \\ ${ }^{3}$ AIDS Care and Prevention Program, Cameroon Baptist Convention Health Services, Cameroon. \\ ${ }^{4}$ Institute of Epidemiology and Preventive Medicine, College of Public Health, National Taiwan \\ University, Taiwan. \\ ${ }^{6}$ HIV/AIDS and Global Health Research Programme, Department of Microbiology, University of \\ Venda, Thohoyandou 0950, South Africa \\ ngongpanemma@yahoo.co.uk,hkimbi@yahoo.co.uk,onyohelias@yahoo.co.uk, \\ godzson1@yahoo.com,bt_yk@yahoo.com,nconica85@gmail.com,Pascal.Bessong@univen.ac.za
}

\begin{abstract}
The aim of this study was to assess the impact of Human Immunodeficiency Virus (HIV) and Plasmodium falciparum genetic diversity on anaemia in HIV-patients attending Care and Treatment Centre in Baptist Hospital Mutengene (BHM). This was a cross-sectional study carried out in BHM from June 2012 to August 2013, consisting of 758 patients. Patients at BHM were interviewed using a structured questionnaire to obtain information on socio-demography. About $3 \mathrm{mls}$ of venous blood were collected, thick and thin blood films for parasite detection and speciation respectively were prepared. Hb concentration and WBC counts were measured to determine anaemic and leucopenic status. First and nested PCR were done on Plasmodium falciparum positive samples to determine Merozoite Surface Protein-1 (MSP-1) and MSP-2 allelic variants. More HIV-patients were malaria positive (34.77\%), anaemic $(31.96 \%$; P<0.001) and leucopenic $(21.13 \%$; $P=0.004)$ as compared to those in malaria mono-infection i.e (16.5\%), (3.03\%) and (0.00\%) respectively. The MSP-1 allelic variants detected were KI (65.22\%), MAD20 (27.54\%) and RO33 (27.54\%) while the MSP-2 allelic variants were FC27 (30.43\%) and 3D7/IC (31.88\%). HIV could predispose patients to more malaria and anaemia while MOI revealed that genetic diversity can cause anaemia. This can assist care givers for the better management of HIV-patients.
\end{abstract}

Keywords: HIV, Malaria, MSP-1, MSP-2, Prevalence, Anaemia.

Abbreviations:

HIV: Human immunodeficiency Virus, BHM: Baptist Hospital Mutengene, CD4+: Cluster of Differentiation 4

PCR: Polymerase Chain Reaction, GMPD: Geometric Mean Parasite Density, Hb: Haemoglobin

WBC: White Blood Cells, PCV: Packed Cell Volume, MSP-1: Merozoite Surface Protein-1

MSP-2: Merozoite Surface Protein-2, MOI: Multiplicity of infection, WHO: World Health Organisation

EDTA: Ethylenediaminetetraacetic acid, LEID: Laboratory for Emerging Infectious Diseases

\section{INTRODUCTION}

HIV and malaria occur concurrently in individuals in sub-Saharan Africa, the epicentre of both infections. HIV/AIDS weakens the body's natural immune response to malaria while the biological response to malaria infection facilitates the advancement of HIV/AIDS [1]. Globally, an estimated 36.9 million people were living with HIV in 2015 [2] meanwhile worldwide reports show that there were 214 million cases of malaria globally in 2015 with 438,000 malaria deaths and the heaviest burden was recorded in the WHO African Region [3]. Due to inadequate disease surveillance in this region, reliable estimates of those co-infected with HIV and malaria are not readily available [4] and the situation needs to be updated. 
HIV infection has been said to predispose patients to more frequent episodes of symptomatic malaria [5], with the highest rates occurring in countries with high HIV prevalence and unstable malaria transmission. HIV-infected individuals could serve as reservoirs of malaria transmission due to more frequent malaria infections which usually result in higher and prolonged parasitaemia and it has also been reported that malaria is significantly associated with anaemia in HIV/AIDS patients [6, 7]. Another concern is the emergence of new parasite strains as a result of prolonged parasitaemia under suboptimal treatment in HIV-infected patients, which could then diffuse into the community [8]. Furthermore, these new parasite strains may possess different virulent characteristics [9] some of which may predispose individuals to anaemia than others. Genetic diversity of $P$. falciparum populations and the complexity of infection have been shown to vary according to the intensity of transmission in different geographical regions [10-14]. The clinical manifestations of malaria are quite diverse and severe anaemia is one of them [15]. Although the molecular basis of severe malaria in recent years has been well studied, the determinants of the clinical outcome of malaria remain unknown [16]. The harm done to human hosts after an infection in terms of morbidity and mortality is considered as an aspect of virulence in malaria [17]. The pathogenesis of anaemia in patients infected with malaria parasites are complex and caused by several factors. They are thought to be as a result of haemolysis of parasitized RBCs, worsened by removal of parasitized red cells, depressed and infective erythropoiesis $[6,18,19]$. The clinical outcome of malaria infections is greatly influenced by multiplicity of infection (MOI) and diversity in parasite virulence and a high MOI has been suggested to increase the risk of anaemia in $P$. falciparum infected persons [20-22]. Finding out the presence of monoclonal and polyclonal infections and/or MOI in HIV-infected individuals will therefore be of utmost importance. Against this background the aim of this work was to determine the impact of Plasmodium falciparum genetic diversity and HIV infection on the prevalence of anaemia in HIV-patients attending the Care and Treatment Centre at Baptist Hospital Mutengene.

\section{Materials AND Methods}

\subsection{Study Site}

The study was carried out in the Baptist Hospital Mutengene (BHM). Mutengene is located at Latitude $4^{\circ} 05^{\prime} \mathrm{N}$, Longitude $9^{\circ} 18^{\prime} \mathrm{E}$ and about 220 meters above sea level, with a total population of about 47,478 inhabitants. It is characterized by mean temperatures of $27.5^{\circ} \mathrm{C}$, a relative humidity of $83.1 \%$ and an annual rainfall of $4000 \mathrm{~mm}$ [23]. Mutengene is found in the Mount Cameroon area of the South West Region in Cameroon which has an equatorial climate with a rainy season that starts in March and ends in October and a dry season that starts in November and ends in February. Patients attending the Care and Treatment Centre come from Mutengene and its environs.

\subsection{Study Design, Duration and Population}

This was a cross sectional study where HIV-infected individuals who came to the Care and Treatment Centre of the BHM were given a health talk on the importance and potential benefits of the study before requesting them to join the study. Only those who accepted were recruited into the study from June 2012 to August 2013. Eligible participants were 1 year of age and above, irrespective of sex and for whom consent was obtained directly or by proxy. Information on whether they were on antiretroviral therapy or not was obtained. All children below 1year of age, pregnant women and those who refused to take part in the study were excluded. A control group of HIV-negative persons was recruited in the out-patient department of the hospital. A total of 758 individuals were enrolled in the study. A venous blood sample was collected from each patient for parasitological, haematological and molecular identification of parasite genotype analyses.

\subsection{Ethical and Biosafety Issues}

An ethical clearance for this work was obtained from the Cameroon Baptist Convention Health Board (CBCHB) Institutional Review Board, Cameroon. Retractable vacutainers were used on the subjects after which they were properly discarded. For the purpose of confidentiality, participants were given codes that were used on their sample collection tubes and results and only members of the research team and supporting health personnel had access to participants' information. Upon presentation of the codes to the laboratory staff participants had access to their results for subsequent follow-up by the physician. The use of name was not accepted in this study and participation was voluntary. Refusal to participate in the study did not affect the services given to the patients in any way. 


\subsection{Methodology}

\subsubsection{Administration of Questionnaire and Clinical Staging to HIV Patients}

A health talk was presented to the patients coming to the BHM Care and Treatment Centre. The purpose of the research was carefully explained to them before requesting for their informed consent to be included in the study. Only those who accepted and signed an informed consent form were included in the study and administered a structured questionnaire to obtain their clinical history. HIV staging was then done by the consulting physician according to the proposed WHO clinical staging classification based on clinical and performance criteria as follows: stage 1 - no symptoms; stage 2 minor signs of immunosuppression; stage 3 - moderate immunosuppression and stage 4 - AIDS [24].

A group of HIV-negative individuals who came to BHM to consult for other illnesses were recruited to serve as controls for the HIV-positive group. They were all tested for HIV to confirm their HIV negative status.

\subsubsection{Blood Specimen Collection}

Three (3) $\mathrm{mL}$ of blood were obtained by venepuncture using ethylenediaminetetraacetic acid (EDTA) tubes for parasitological examination by microscopy, haematological analysis and molecular identification of parasite genotypes. The blood was gently mixed in the tubes immediately after blood collection to avoid clotting. Plasma was separated by centrifugation within six hours after blood collection at the hospital and taken to the Laboratory for Emerging Infectious Diseases (LEID) at the University of Buea where they were stored at $-80^{\circ} \mathrm{C}$. Red cell pellets were stored at $-20^{\circ} \mathrm{C}$. All data forms were reviewed on site for their completeness and matched to blood samples before transportation of the samples to LEID at the University of Buea.

\subsubsection{Haemoglobin Measurement and Classification of Anaemia}

Haemoglobin $(\mathrm{Hb})$ concentration was measured using a Urit12 haemoglobinometer. Hb strips were inserted into the haemoglobinometer and using a micropipette, about $20 \mu \mathrm{L}$ of blood was placed on the haemoglobinometer following the manufacturer's instructions. The $\mathrm{Hb}$ value was displayed automatically by the haemoglobinometer and read in grams per decilitre $(\mathrm{g} / \mathrm{dL})$. Classification and severity of anaemia was done according to WHO [25]. Haemoglobin values less than $11 \mathrm{~g} / \mathrm{dl}$ were considered anaemic. Anaemia severity was classified as follows: Hb values between 10.0-10.9 g/dL, $7.0-9.9 \mathrm{~g} / \mathrm{dL}$ and $<7.0 \mathrm{~g} / \mathrm{dL}$ were considered as mild, moderate and severe anaemia respectively [25].

\subsubsection{CD+4 Count Measurement}

CD4+ counts were measured using the CyFlow ${ }^{\circledR}$ Counter (Partec GmbH, Münster, Germany) [26]. CD4 T-cell counts were categorised as low or advanced stage $(<200 / \mu 1)$, moderate or chronic stage $(200-499 / \mu 1)$ and high or asymptomatic stage $(\geq 500 / \mu 1)[27]$.

\subsubsection{Determination of Packed Cell Volume (PCV)}

Blood was collected into a heparinized capillary tube to about three quarters its length for the estimation of packed cell volume (PCV). One end of the tube was sealed with plasticine. These tubes were well arranged in a mico-haematocit centrifuge with the plugged end away from the centre of the centrifuge. Centrifugation was done at $12000 \mathrm{rpm}$ for five minutes. The tubes were placed on a microhaematocrit reader and the haematocrit was read following the manufacturer's instructions on the micro-haematocrit reading device [28].

\subsubsection{White Blood Cell Count (WBC) Measurement}

To $20 \mu 1$ of blood in a cuvette, $0.4 \mathrm{ml}$ of diluting fluid (Turk's solution) was added and mixed for 2 to 3 minutes to lyse the red and white blood cells leaving the leucocyte nuclei intact. An improved Neubauer chamber was filled with the mixed solution and placed in a moist petri dish to avoid evaporation of the solution. The mixture was allowed to stand for 3 to 5 minutes for the cells to settle. Using the low power objective of an Olympus ${ }^{\circledR}$ BX 40F light microscope (Olympus Optical Co. Ltd., Japan), the cells were counted in the four large corner squares $\left(4 \mathrm{~mm}^{2}\right)$ observing the criteria for inclusion and exclusion of cells touching the borders [28]. Leucopenia was defined as WBC $<3500$ cells $/ \mathrm{mm}^{3}$. 


\subsubsection{Preparation and Staining of Blood Films for Detection and Speciation of P. falciparum}

Using a micropipette. $10 \mu \mathrm{L}$ of blood was picked from each EDTA tube and placed on one side of a clean labelled slide that was free from dirt, grease and finger prints for the thick blood film. The drop of blood was spread out by stirring to form a smear. Another small drop of blood was placed about $15 \mathrm{~mm}$ from the thick blood film towards the centre of the slide for the thin film. A clean spreader was lowered at an angle of $30^{\circ}$ in front of the drop and drawn backwards until it touched the small drop of blood. As the blood spread along the edge of the spreader, the spreader was pushed forward steadily and rapidly along the length of the slide to form a tail at the end of the film. This process was repeated for all the other samples that were collected. The slides were air-dried properly in order to avoid the thick blood film from washing off during the staining process. Prior to staining, the thin films were fixed in methanol for about 2-3 seconds and allowed to air-dry.

Giemsa stain stock diluted in 1:20 in buffered distilled water was used for staining both films. The slides were placed on a staining rack with the films facing upwards. Both films were flooded with Giemsa and stained for 15 minutes. The stains were washed off using buffered water and allowed to air-dry in a slanting position on a draining rack.

The Giemsa-stained thick smears were first examined under X100 (oil immersion) objective of an Olympus ${ }^{\circledR}$ BX 40F light microscope (Olympus Optical Co. Ltd., Japan). Slides were considered positive if asexual forms and or gametocytes of any Plasmodium species were observed in the blood films. When thick smears were positive, the corresponding thin films were observed to determine the species of Plasmodium present. Malaria parasites were counted against 200 leucocytes in the thick film. The parasite density was recorded as the number of asexual parasites per micro litre of blood $\mathrm{X}$ leucocyte count of the individual's WBC count $/ \mu \mathrm{L}$ of blood [28].

Parasite density $=$ number of parasites $\mathrm{x}$ individual's WBC count $/ 200$ white blood cells $/ \mu \mathrm{L}$.

\subsubsection{Genotyping of P. falciparum}

\section{DNA extraction}

DNA was extracted and purified using a standardized QIAamp DNA blood midi kit (QIAGEN Ltd, Crawley, UK) following the manufacturer's instructions. The total DNA eluted was then aliquoted into ependorf tubes and kept at $-20^{\circ} \mathrm{C}$ for use in DNA amplification.

\section{P. falciparum MSP-1 and MSP-2 gene amplification}

Block 2 of MSP-1 and block 3 of MSP-2 of P. falciparum were genotyped by allele-specific nestedPCR to analyse the population diversity of the parasite as follows: In the first PCR reaction for each sample, $2 \mu \mathrm{L}$ of 10x PCR buffer, $0.125 \mu \mathrm{L}$ deoxynucleotide triphosphates (dNTP's), $0.1 \mu \mathrm{L}$ of Taq polymerase, $0.6 \mu \mathrm{L}$ of $\mathrm{MgCL}_{2}, 0.4 \mu \mathrm{L}$ of the forward and reverse primer sets for each polymorphic region, $1 \mu \mathrm{L}$ of total DNA template and $15.375 \mu \mathrm{L}$ of PCR water were prepared for a total volume of $20 \mu \mathrm{L}$ reaction.

After initial denaturation at $95^{\circ} \mathrm{C}$ for 5 minutes, 25 cycles of amplification with Cycling conditions in a BioRad thermo cycler $\left(\mathrm{T} 100^{\mathrm{TM}}\right)$ were as follows: denaturation at $94^{\circ} \mathrm{C}$ for 1 minute, annealing at $58^{\circ} \mathrm{C}$ for 2 minutes, extension at $72^{\circ} \mathrm{C}$ for 2 minutes and final extension at $72^{\circ} \mathrm{C}$ for 2 minutes. When amplification was complete, it got to $4^{\circ} \mathrm{C}$ for infinity. Using as template the products of the first PCR reaction, the same concentrations were used for the nested reaction. The cycling conditions were also the same for nested PCR except for the second annealing step which took place at $61^{\circ} \mathrm{C}$ for 2 minutes and the entire step went on for 30 times. The primer sequences for the first round and family-specific nested PCR for MSP-1 variants (K1, MAD20 and RO33) and MSP-2 variants (FC27 and 3D7/IC) were used as described by Snounou et al. [29].

The PCR products were verified for right quantities and sizes by running on a $2 \%$ agarose gel at $100 \mathrm{~V}, 300 \mathrm{~mA}$ for 45 minutes and a gel picture was taken and viewed using a trans-illuminator.

\subsubsection{Statistics}

Pearsons Chi-square test $\left(\chi^{2}\right)$ was performed to measure the relationship between parameters and malaria parasite and anaemic status. The Student- $t$ test was performed to compare data across different categories. For these statistical analyses, PASW Statistics 18.0 SPSS Inc. software was used. 
The Impact of HIV and Plasmodium falciparum Genetic Diversity on Anaemia in HIV-patients Attending Care and Treatment Centre at Baptist Hospital Mutengene

Multiplicity of infection (MOI i.e mean minimum number of different parasite genotypes per infected subject) was estimated by dividing the total number of MSP-1 PCR fragments representing different genotypes by the number of infected subjects.

3. 56 samples were genotyped for MSP-1 $(81.16 \%, 56 / 69)$ while 35 were genotyped for the MSP-2 RESULTS

\subsection{Characteristics of the Study Population}

A total of 758 patients (558 HIV-positive and 200 HIV-negative patients) were recruited into the study. Overall, 34.77\% (194/558) of the HIV-positive participants were malaria parasite positive while $65.23 \%$ (364/558) were malaria parasite negative. In the control group of HIV-negative persons $16.5 \%$ (33/200) were malaria parasite positive while $83.5 \%$ (167/200) were malaria parasite negative. Out of the 194 malaria positive HIV samples identified by microscopy, 147 were genotyped for $P$. falciparum genetic diversity using Polymerase Chain Reaction (PCR) and 69 of them were positive for MSP-1 and MSP-2 allelic families (46.94\%, 69/147). A total of gene (50.72\%, 35/69) (Figure 1).

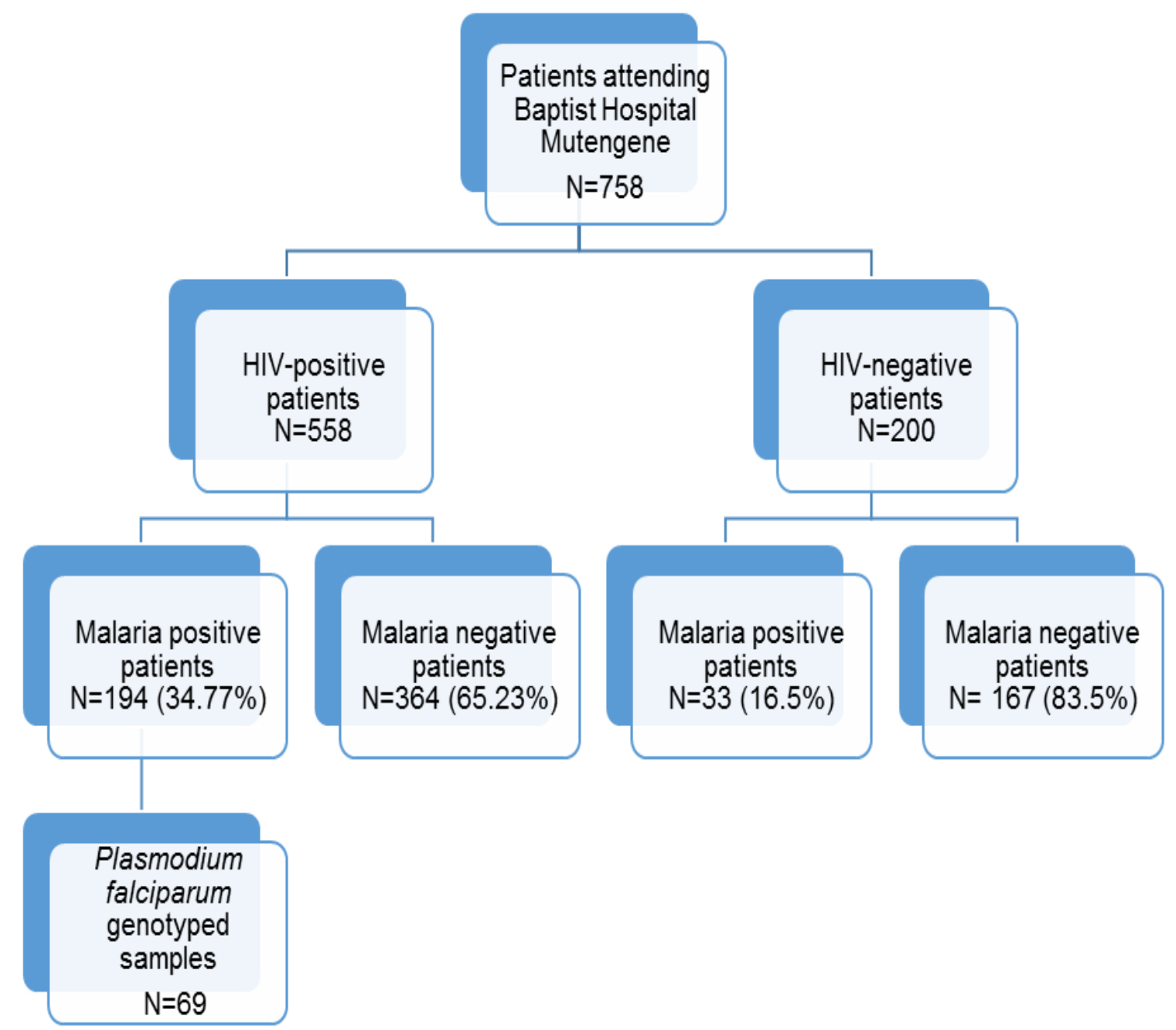

Figure1. Characteristics of the study population

\subsection{The Impact of HIV Infection on Haematological Parameters and Malaria Parasite Infection in HIV-patients in the Study Population}

Anaemia prevalence was significantly higher $\left(\chi^{2}=11.77 ; \mathrm{P}<0.001\right)$ in $\mathrm{HIV} /$ malaria co-infected individuals $(31.96 \%, 62 / 194)$ when compared with HIV-negative individuals that had malaria monoinfection $(3.03 \%, 1 / 33)$ as shown in Table 1 . Anaemia was significantly associated [Odds Ratio (OR at $95 \%$ confidence interval, $\mathrm{CI})=0.07(0.009-0.498), \mathrm{P}=0.008]$ with having a HIV/malaria coinfection than malaria mono-infections as shown in table 2. 
The only subject who had malaria mono-infection had moderate anaemia, and there was no case of severe anaemia. However, there were cases of severe anaemia $(4 / 62,6.45 \%)$ in the HIV/malaria coinfected individuals (Table 1).

The prevalence of leucopenia was significantly higher $\left(\chi^{2}=8.51 ; \mathrm{P}=0.004\right)$ in HIV/malaria coinfected cases $(21.13 \%, 41 / 194)$ than in the control group with malaria mono-infections $(0 \%, 0)$. Patients who were co-infected with HIV/malaria were 8 times more likely to have leucopenia [OR $(95 \% \mathrm{CI})=8.58(1.138-64.64), \mathrm{P}=0.04]$ than those infected with malaria alone as shown in table 2 .

The mean packed cell volume of HIV/malaria co-infected individuals (33.44 \pm 5.76$)$ was significantly lower $(\mathrm{t}=-8.19 ; \mathrm{P}<0.001)$ than that of malaria mono-infected individuals $(42.52 \pm 6.61)$ as illustrated in Table 1.

Although the difference was not significant $(\mathrm{t}=-1.50 ; \mathrm{P}=0.14)$, the mean WBC of HIV/malaria coinfected individuals was however lower $(4632 \pm 2201.9)$ than that of malaria mono-infected individuals (5230.3 \pm 1522.6 ). ) Table 1 also shows that the geometric mean parasite density (GMPD)/parasites per $\mu \mathrm{l}$ in HIV/malaria co-infected individuals was lower (395.18) than that in malaria mono-infected individuals (501.14) but the difference was however not significant $(\mathrm{t}=-0.50 ; \mathrm{P}=0.96)$ (Table 1).

Table1. The impact of HIV infection on malaria parasite infection with respect to haematological factors of HIV/AIDS patients in the study population

\begin{tabular}{|c|c|c|c|c|}
\hline Characteristic & Category & $\begin{array}{c}\text { HIV/Malaria } \\
\text { co-infected patients } \\
(\%) \text { n=194 }\end{array}$ & $\begin{array}{c}\text { Malaria } \\
\text { mono- infected patients } \\
(\%) \\
\mathbf{n}=\mathbf{3 3}\end{array}$ & Statistical tests \\
\hline \multirow[t]{2}{*}{ Anaemic status } & Non anaemic & $132(68.04)$ & $32(96.97)$ & \multirow{2}{*}{$\begin{array}{l}\chi^{2}=11.77 ; \\
P<0.001\end{array}$} \\
\hline & Anaemia & $62(31.96)$ & $1(3.03)$ & \\
\hline \multirow{3}{*}{$\begin{array}{l}\text { Anaemia } \\
\text { severity }\end{array}$} & Severe & $4(6.45)$ & $0(00.0)$ & \multirow{3}{*}{$\chi^{2}=0.71 ; P=0.70$} \\
\hline & Moderate & $36(58.06)$ & $1(100.0)$ & \\
\hline & Mild & $22(35.48)$ & $0(00.0)$ & \\
\hline \multirow[t]{2}{*}{ Leucopenia } & Yes & $41(21.13)$ & $0(00.0)$ & \multirow[t]{2}{*}{$\chi^{2}=8.51 ; P=0.004$} \\
\hline & No & $153(78.87)$ & $33(100.0)$ & \\
\hline PCV & Mean \pm SD & $33.44 \pm 5.76$ & $42.52 \pm 6.61$ & $\mathrm{t}=-8.19 ; \mathrm{P}<0.001$ \\
\hline WBC count & Mean \pm SD & $4632 \pm 2201.9$ & $5230.3 \pm 1522.6$ & $\mathrm{t}=-1.50 ; \mathrm{P}=0.14$ \\
\hline $\begin{array}{l}\text { GMPD } \\
\text { (/ } \mu 1 \text { of blood) }\end{array}$ & Mean & 395.18 & 501.14 & $\mathrm{t}=-0.50 ; \mathrm{P}=0.96$ \\
\hline
\end{tabular}

Table2. HIV infection as a predictor of anaemia and leucopenia in HIV-positive individuals in the study population

\begin{tabular}{|l|c|c|c|c|c|}
\hline Characteristic & Category & $\begin{array}{c}\text { HIV/Malaria } \\
\text { co-infected } \\
\text { patients (\%) } \\
\mathbf{n = 1 9 4}\end{array}$ & $\begin{array}{c}\text { Malaria } \\
\text { mono-infected } \\
\text { patients } \\
(\boldsymbol{\%}) \mathbf{n = 3 3}\end{array}$ & OR (95\% CI) & $\begin{array}{c}\text { P } \\
\text { value }\end{array}$ \\
\hline \multirow{2}{*}{$\begin{array}{l}\text { Anaemic } \\
\text { status }\end{array}$} & Non anaemic & $132(68.04)$ & $32(96.97)$ & 0.07 & \multirow{2}{*}{0.008} \\
\cline { 2 - 4 } Leucopenia & Anaemia & $62(31.96)$ & $1(3.03)$ & $(0.009-0.498)$ & \multirow{2}{*}{$\begin{array}{c}8.58 \\
(1.138-64.64)\end{array}$} \\
\cline { 2 - 4 } & Yes & $41(21.13)$ & $0(00.0)$ & $33(100.0)$ & 0.04 \\
\hline
\end{tabular}

\subsection{The Impact of P. falciparum Genetic Diversity on Anaemia in HIV-infected Patients}

Among the 147 malaria parasite positive samples that were genotyped for P. falciparum 69 samples were positive for MSP-1 and MSP-2 allelic families. Fifty-six samples were amplified for MSP-1 gene and thirty-five for MSP-2 gene. The K1 allelic variant of MSP-1 was the most frequent $(65.22 \%$, 45/69), followed by MAD20 (27.94\%, 19/69) and RO33 (27.94\%, 19/69) while among MSP 2 allelic variants, 3D7/IC was slightly more prevalent $(31.88 \%$, 22/69) than FC27 $(30.43 \%, 21 / 69)$. The prevalence of anaemia was highest among individuals with the FC27 allelic variant genotype (47.62\%) and least in individuals with 3D7/IC genotype (28.57\%) as illustrated in Figure 2. 
The Impact of HIV and Plasmodium falciparum Genetic Diversity on Anaemia in HIV-patients Attending Care and Treatment Centre at Baptist Hospital Mutengene

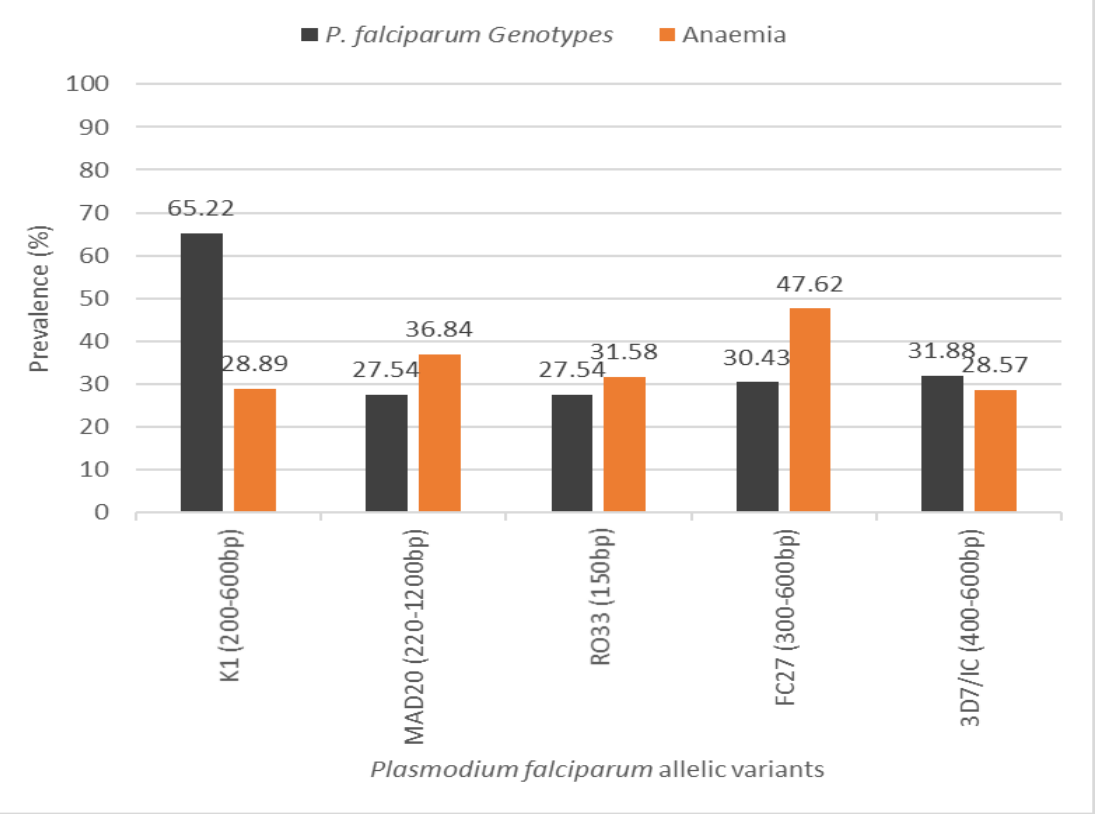

Figure2. Relationship between P. falciparum allelic variants and anaemia in the study

Among the different allelic families of MSP-1 in the study, the most prevalent was K1 $(48.21 \%$, 27/56), while the least prevalent was MAD20/RO33 (3.57\%, 2/56). In the different allelic families of MSP-2 recorded, FC27 had the highest prevalence (44.74\%, 17/38) while FC27/3D/IC was the least prevalent $(23.68 \%, 9 / 38)$ as indicated in Table 3.

Although the difference was not significant $\left(\chi^{2}=3.85 ; \mathrm{P}=0.70\right)$, the highest prevalence of anaemia $(60 \%, 3 / 5)$ was recorded in the RO33 allelic family of MSP-1, followed by the MAD/RO33 allelic family $(50 \%, 1 / 2)$ and the least was recorded in both K1/MAD20 and K1/MAD20/RO33 allelic families $(20 \%, 1 / 5)$ as shown in Table 3.

Anaemia prevalence was highest among patients of the FC27 allelic family of the MSP-2 gene $(52.94 \%, 9 / 17)$ followed by the FC27/3D/IC allelic family $(33.33 \%, 3 / 9)$ and least among patients having the 3D/IC allelic family of MSP-2 gene $(25 \%, 3 / 12)$. However, the difference was not significant $\left(\chi^{2}=2.48, \mathrm{P}=0.29\right)$ as illustrated in Table 3 .

Table3. Distribution and relationship between anaemia and allelic families of MSP-1 and MSP-2 genes in the study population

\begin{tabular}{|c|c|c|c|c|c|}
\hline $\begin{array}{l}\text { Allelic } \\
\text { family }\end{array}$ & Type & $\mathrm{N}=56(\%)$ & $\begin{array}{c}\text { Number of non- } \\
\text { anaemic patients } \\
(\%)\end{array}$ & $\begin{array}{c}\text { Number of } \\
\text { anaemic patients } \\
(\%)\end{array}$ & Tests \\
\hline & K1 & $27(48.21)$ & $20(74.07)$ & $7(25.93)$ & \multirow{7}{*}{$\begin{aligned} \chi^{2} & =3.85 \\
P & =0.70 \\
d f & =6\end{aligned}$} \\
\hline \multirow[t]{7}{*}{ MSP-1 } & MAD20 & $3(05.36)$ & $2(66.67)$ & $1(33.33)$ & \\
\hline & RO33 & $5(08.93)$ & $2(40.00)$ & $3(60.00)$ & \\
\hline & K1/MAD20 & $9(16.07)$ & $5(55.57)$ & $4(44.44)$ & \\
\hline & K1/RO33 & $5(08.93)$ & $4(80.00)$ & $1(20.00)$ & \\
\hline & MAD20/RO33 & $2(03.57)$ & $1(50.00)$ & $1(50.00)$ & \\
\hline & K1/MAD20/RO33 & $5(08.93)$ & $4(80.00)$ & $1(20.00)$ & \\
\hline & & $\mathrm{N}=38$ & & & \\
\hline \multirow[t]{3}{*}{ MSP-2 } & FC27 & 17 (44.74) & $8(47.06)$ & $9(52.94)$ & \multirow{3}{*}{$\begin{array}{c}\chi^{2}=2.48 \\
P=0.29 \\
d f=2\end{array}$} \\
\hline & $3 \mathrm{D} / \mathrm{IC}$ & $12(31.58)$ & $9(75.00)$ & $3(25.00)$ & \\
\hline & FC27/3D/IC & $09(23.68)$ & $6(66.67)$ & $3(33.33)$ & \\
\hline
\end{tabular}

In the MSP-1 gene of $P$. falciparum, monoclonal infections were more prevalent $(49.28 \%, 34)$ than polyclonal infections $(31.88 \%, 22)$. Similarly in the MSP-2 gene, monoclonal infections were more prevalent $(42.03 \%, 29)$ than polyclonal infections $(13.04 \%, 9)$. There was a significant difference in the prevalence of monoclonal as compared to polyclonal infections of MSP-1 and MSP-2 genes $\left(\chi^{2}=13.21 ; \mathrm{P}=0.001\right)$. MOI was higher in MSP-1 gene $(1.93 \pm 0.2)$ than MSP-2 gene (1.4 \pm 0.12$)$ (Table 4). 
Emmaculate Lum et al.

Table4. Multiplicity and type of infection for MSP-1 and MSP-2 genes of P. falciparum in the study population

\begin{tabular}{|c|c|c|c|c|c|}
\hline GENE & $\begin{array}{c}\text { Mean } \\
\text { MOI } \mathbf{\pm} \text { SD }\end{array}$ & $\begin{array}{c}\text { Monoclonal } \\
\text { infection n }(\%)\end{array}$ & $\begin{array}{c}\text { Polyclonal } \\
\text { infection n }(\boldsymbol{\%})\end{array}$ & $\begin{array}{c}\text { No infection } \\
\mathbf{n}(\boldsymbol{\%})\end{array}$ & $\begin{array}{c}\text { Total } \\
\mathbf{N}(\boldsymbol{\%})\end{array}$ \\
\hline MSP-1 & $1.93 \pm 0.2$ & $34(49.28)$ & $22(31.88)$ & $13(18.84)$ & $69(100)$ \\
\hline MSP-2 & $1.4 \pm 0.12$ & $29(42.03)$ & $9(13.04)$ & $31(13.04)$ & $69(100)$ \\
\hline
\end{tabular}

$\chi^{2}=13.21 ; \mathrm{p}=0.001$

\subsection{The Impact of HAART on Anaemia in HIV-infected persons}

More patients were on HAART $(76.81 \%, 53 / 69)$ than those that were not on HAART $(23.19 \%$, $16 / 69)$. Although the difference was not significant $\left(\chi^{2}=1.35, P=0.25\right)$ a higher prevalence of anaemia was however recorded among those that were not on HAART $(43.75 \%, 7 / 16)$ when compared with those that were on HAART $(28.30 \%)$ as illustrated in Table 5.

Table5. Relationship between HAART therapy and anaemia in the study population

\begin{tabular}{|c|c|c|c|c|}
\hline Patients on HAART & $\begin{array}{l}\mathrm{N}=69 \\
\mathrm{n}(\%)\end{array}$ & Number non-anaemic (\%) & Number Anaemic (\%) & Test \\
\hline Yes & $53(76.81)$ & $38(71.70)$ & $15(28.30)$ & \multirow{2}{*}{$\begin{array}{c}\chi^{2 .} \\
=1.35 \\
\mathrm{P}=0.25\end{array}$} \\
\hline No & $16(23.19)$ & $9(56.25)$ & $7(43.75)$ & \\
\hline
\end{tabular}

\section{DisCuSSION}

HIV and malaria infection can occur concurrently in patients and constitute two of the most important diseases of public health importance in sub-Saharan Africa including Cameroon. This study was designed to investigate the impact of HIV and Plasmodium falciparum genetic diversity on anaemia in HIV-patients attending the care and treatment centre at BHM from June 2012 to August 2013.

The assessment of the impact of HIV on haematological parameters of HIV/malaria co-infected individuals using HIV-negative persons as control, revealed that anaemia was significantly associated $(\mathrm{P}<0.001)$ with co-infection of HIV/malaria when compared with malaria mono-infected controls. This suggests that HIV probably predisposes individuals to more anaemia when co-infected with malaria as compared to those that are infected with malaria alone. Malaria on its own causes anaemia and the potential mechanisms contributing to malarial anaemia can be divided into two categories which include increased destruction of parasitized as well as un-parasitized erythrocytes through immune-mediated lysis, phagocytosis and splenic sequestration. Secondly, there is a decrease of erythrocyte production through dyserythropoiesis and bone marrow suppression, inadequate reticulocyte production, effects of inflammatory cytokines and effects of parasite factors. It has been reported that impaired haematopoiesis, immune-mediated cytopenias, and altered coagulation mechanisms do occur in HIV-infected individuals, probably as a result of HIV infection itself, as sequelae of HIV-related opportunistic infections or malignancies, or as a consequence of treatments used for HIV infection and related condition. This report is similar to that of a study carried out in Lagos Nigeria [30] where patients co-infected with malaria and HIV were more likely to be anaemic.

There was no case of severe anaemia among the control group with malaria mono-infection but there were cases of severe anaemia among HIV/malaria co-infected individuals. This further supports the fact that HIV infection can likely worsen the anaemic state of persons with HIV/malaria co-infection as compared to those infected with malaria alone. It would therefore be of interest to use a larger cohort and longitudinal studies to investigate further in order to ascertain the impact of HIV on anaemia in HIV/malaria co-infected persons.

Our findings showed that leucopenia was significantly associated ( $\mathrm{p}=0.04)$ with HIV/malaria coinfection compared with malaria mono-infected persons. This probably indicates that there is depletion of white blood cells (WBC) when a patient is co-infected with both malaria and HIV. Low CD4+ T-lymphocyte counts have been associated with a variety of conditions including many viral infections and parasitic infections.

The mean PCV as well as mean WBC count were lower in HIV/malaria co-infected participants than in those infected with malaria alone. WBC counts during malaria are generally characterized as being low to normal which is a phenomenon that is widely thought to reflect the localization of leukocytes away from the peripheral circulation and to the spleen and other marginal pools, rather than actual 
depletion or stasis. Leucocytosis is typically reported in a fraction of cases and may be associated with concurrent infections and/or poor prognosis [31,32]. Earlier studies had established the association between peripheral leucopenia and malaria [31] and between peripheral leucocytosis and severe cases [32]. They reported that when fever begins during an initial infection, the WBC count decreases to its minimum level at roughly the same time and infection becomes detectable by microscopy [33, 34], although neither of these involve naturally acquired infections. Other studies also reported that leucopenia, even in mild cases, is punctuated by a transient leucocytosis, either during or between febrile paroxysms [35] and leucocytosis has been commonly reported in P. falciparum-infected African children [36]. HIV invasion of myeloid precursors or of cells producing granulocytestimulating cytokines have been suggested as one of the causes of leucopenia [37].

GMPD was similar in HIV/malaria co-infected individuals and in the controls with mono-infections of malaria. This was contrary to expectation and cannot be readily explained because studies on HIV infection have been associated with increase in clinical malaria and parasitaemia [38, 39].

Apart from investigating if HIV on its own could be a predisposing factor for anaemia and other haematological changes in HIV-infected persons, we also assessed if the genetic diversity of the infecting malaria parasite and HAART treatment could have an impact on anaemia in these patients. The identification of more than one genotype of MSP-1 (block 2) and MSP-2 (block 3) genes among the samples portrayed the genetic diversity of parasite genotypes that exist among patients infected with $P$. falciparum. This is consistent with other studies where allelic variants of MSP-1 and MSP-2 have been reported in other countries [13, 28, 39, 40-42] though not specifically among HIV-patients. The genetic diversity of $P$. falciparum populations and the complexity of infection have been reported to vary according to the intensity of transmission in different geographical areas with the existence of size polymorphism as identified by the size of the PCR amplified fragment [10-14].

Individuals who possessed the FC27 genetic variant of MSP-2 gene had the highest prevalence of anaemia when compared with prevalence of anaemia among individuals with the other genotypes. This suggests that the FC27 genotype may possess some characteristics that predispose the individuals to anaemia than others. The prevalence of anaemia among participants with these various genotypes suggests that there could be some existing association between MSP-1/MSP-2 genotypes and anaemia among HIV-patients. A high multiplicity of infection (MOI) of $P$. falciparum has been suggested to increase the risk of clinical outcome of malaria parasite infections especially anaemia [20-22]. In the allelic families of MSP-1, KI was the most prevalent followed by K1/MAD20 allelic family while the least was MAD20/RO33. This is similar to findings in studies carried out in Southwest Nigeria [11, 43]. However, this is in contrast to the findings in Thailand [29] and Myanmar [44] which showed that MAD20 was the predominant allelic family.

Anaemia was most prevalent in the RO33 allelic family, followed by MAD20/RO33 and K1/MAD20 allelic families although there was no significant difference between MSP-1 allelic families. Since structure is directly related to function, this may suggest why some allelic families may expose patients to more anaemia than others.

Among the MSP-2 allelic families, FC27 was most prevalent while the least was the FC27/3D/IC allelic family. This is similar to results of Atroosh et al., [41] though they had 3D allelic family as the most prevalent. FC27 which was the most prevalent also had the highest anaemic prevalence but there was no significant relationship between MSP-2 allelic families and anaemia in the study.

Overall, there were more anaemic cases in MSP-1 than MSP-2 genes and MOI was also higher in MSP-1 than MSP-2 gene. This is consistent with other findings where MOI has been shown to increase with anaemia [20-22]. There were more monoclonal as well as polyclonal infections in MSP-1 compared to the MSP-2 gene with a significant association. Some other studies have reported a significant association between the complexity of infection and polyclonal infections with asymptomatic malaria [44]. It has also been reported that polyclonal infections are found in holoendemic and meso-endemic areas [45] like our study area Mutengene, Cameroon and that probably explains why high MOI is associated with anaemia or low haemoglobin levels [20-22].

It is worth noting that anaemia in HIV/malaria co-infected patients may not necessarily be as a result of the HIV infection or infecting malaria parasite only, but other confounding factors could be implicated since the causes of anaemia are usually multifactorial. Other pathologies such as helminth 
and protozoal infections, haemoglobinopathies and some cancers among others are known to sometimes cause anaemia though these were not investigated in this study.

In this study there was no significant difference in prevalence of anaemia between those on HAART and those not on HAART. However, it was earlier reported that one of the earlier used antiretroviral drugs, zidovudine is associated with anaemia as a result of haematological toxicity in the bone marrow which slows down the proliferation of blood progenitor cells. Therefore, HIV-patients treated with the drug have to be followed up closely to avoid such toxicity [46]. The use of HAART has been associated with an increase in haemoglobin values as it decreases viral replication in HIV-patients thereby slowing down the progression of the disease. This consequently leads to a reduction in anaemia and has several benefits for the HIV-patient such as the improvement in functional status, energy levels and fatigue and an overall improvement in the quality of life [47].

The limitations of this study include the fact that data on CD4+ counts of HIV negative individuals could not be obtained due to financial constraints. Other possible infections that could have contributed to anaemia were not investigated in this study and they might have confounded our findings.

\section{Conclusions}

Malaria parasite prevalence, anaemia as well as anaemia severity were more prevalent in HIV/malaria co-infected-patients than in malaria mono-infected patients. The most prevalent MSP-1 and MSP-2 allelic families in the study were $\mathrm{K} 1$ and FC27 respectively. The allelic family in the study that recorded the highest prevalence of anaemia was FC27. MOI was higher in MSP-1 than MSP-2 genes. Since MOI and diversity in parasite virulence are important factors that contribute to the clinical outcome of malaria, caregivers should always assess to ensure that patients are not infected with concurrent malaria parasite which can lead to increase disease burden on the patient. Knowing the patients malaria status will assist the care givers to manage and treat co-infected patients promptly and this will improve on the health of the patients involved.

\section{ACKNOWLEDGEMENTS}

We thank the entire team of the Molecular Genetics Laboratory, University of Venda, South Africa for assistance - financially, materially and equipments used in carrying out the molecular aspects of this work. We equally appreciate Prof. Lehman G. Leopold and the PARTEC Laboratory, Douala, Cameroon for assistance in carrying out the CD4+ count for the study. We are equally grateful to the Laboratory for Emerging Infectious Diseases, University of Buea for provision of laboratory space for the storage of all samples used for molecular work and also to Prof. Ndip Roland who critically reviewed the study proposal. We acknowledge the assistance of Tchakunte Simeon for the statistical analysis of the data.

\section{REFERENCES}

[1] Hewitt K., Steketee R., Mwapasa V., Whitworth J. and French N. Interactions between HIV and malaria in non-pregnant adults: evidence and implications, AIDS, 20:1993 - 2004. (2006).

[2] UNAIDS report on global AIDS epidemic (2015).

[3] WHO, 2015. World Malaria Report, fact sheet (2015).

[4] UNAIDS, 2007. Annual Report, knowing your epidemic (2007).

[5] Kamya M.R., Gasasira A. F., Yeka A. et al., Effect of HIV-1 infection on antimalarial treatment outcomes in Uganda: a population-based study. Journal of Infectious Diseases, 193(1) 9-15 (2006).

[6] Erhabor O., Babatunde S., and Uko K.E. Some Haematological Parameters in Plasmodial Parasitized HIV-Infected Nigerians. Nigerian Journal of Medicine 15(1):52-5 (2006)

[7] Nkuo-Akenji T., Tevoufouet E.M., Nzang F., Ngufor N. and Fon E. High prevalence of HIV and malaria co-infection in urban Douala, Cameroon. Afr J AIDS Res. 7(2):229-32 (2008).

[8] Lloyd-Smith J.O., Poss M. and Grenfell B.T. HIV-1/parasite co-infection and the emergence of new parasite strains. Parasitology, 135: 795-806 (2008).

[9] de Roode J.C., Helinski M.E., Anwar M.A and Read A.F. Virulence and competitive ability in genetically diverse malaria infections. Proc Natl Acad Sci U.S.A 102(21):7624-7628 (2005). 
The Impact of HIV and Plasmodium falciparum Genetic Diversity on Anaemia in HIV-patients Attending Care and Treatment Centre at Baptist Hospital Mutengene

[10] Engelbrecht F., Felger I., Genton B., Alpers M. and Beck H. P. Plasmodium falciparum: malaria morbidity is associated with specific merozoite surface antigen 2 genotypes. Exp Parasitol, 81, 90-6 (1995).

[11] Amodu O. K., Adeyemo A. A., Ayoola O. O., Gbadegesin R. A., Orimadegun A. E., Akinsola A. K., Olumese P. E. and Omotade O. O. Genetic diversity of the msp-1 locus and symptomatic malaria in south-west Nigeria. Acta Trop, 95: 226-32 (2005).

[12] Amodu O. K., Oyedeji S. I., Ntoumi F., Orimadegun A. E., Gbadegesin R. A., Olumese P. E. and Omotade O. O. Complexity of the msp2 locus and the severity of childhood malaria, in southwestern Nigeria. Ann Trop Med Parasitol, 102, 95-102 (2008).

[13] Wanji S., Kengne-Ouafo A.J., Eyong E.E.J., Kimbi H.K., Tendongfor N., Ndamukong-Nyanga J.L., Nana-Djeunga H.C., Bourguinat C., Sofeu-Feugaing D.D. and Charvet C.L. Genetic Diversity of Plasmodium falciparum Merozoite Surface Protein-1 Block 2 in Sites of Contrasting Altitudes and Malaria Endemicities in the Mount Cameroon Region.Am. J. Trop. Med. Hyg., 86(5), pp. 764-774 (2012).

[14] Hamid M.M., Mohammed S.B. and El Hassan I.M. Genetic Diversity of Plasmodium falciparum Field Isolates in Central Sudan Inferred by PCR Genotyping of Merozoite Surface Protein 1 and 2. N Am J Med Sci, 5:95-101 (2013).

[15] Miller L.H., Baruch D.I., Marsh K. and Doumbo O.K. The pathogenic basis of malaria. Nature 415 (6872):673-679 (2002).

[16] Conway D.J. Molecular epidemiology of malaria. Clin Microbiol Rev 20(1):188-204 (2007).

[17] Read A. Evolution of virulence: malaria, a "Case Study". In: Nesse R (ed) Evolution and Medicine: How New Applications Advance Research and Practice, The Biomedical \& Life Sciences Collection. Henry Stewart Talks Ltd, London (2007).

[18] Richards M.W., Bechran R.H. and Dherty J.I. Haematologic changes in acute, imported Plasmodium falciparum malaria. American Journal of Tropical Medicine, 59:859 (1998).

[19] John C.C., Park G.S., Sam-Agudu N., Opoka R.O. and Boivin M.J. Elevated serum levels of IL1ra in children with Plasmodium falciparum malaria are associated with increased severity of disease. Cytokine, 41:204-208 (2008).

[20] May J., Falusi A.G., Mockenhaupt F.P. et al. Impact of sub-patent multi-species and multi-clonal plasmodial infections on anaemia in children from Nigeria. Transactions of the Royal Society of Tropical Medicine and Hygiene, 94: 399-403 (2000).

[21] Beck S., Mockenhaupt F.P., Bienzle U., Eggelte T.A., Thompson W.N. and Stark K. Multiplicity of Plasmodium falciparum infection in pregnancy. American Journal of Tropical Medicine and Hygiene, 65: 631-636 (2001).

[22] Mockenhaupt F.P., Ehrhardt S., Eggelte TA., Markert M., Anemana S., Otchwemah R. and Bienzle U. Plasmodium falciparum multiplicity correlates with anaemia in symptomatic malaria. Tropical Medicine and International Health, volume 8 no 10 pp 857-859 (2003).

[23] Cameroon Development Corporation (CDC) weather records (2004).

[24] W.H.O case definitions of HIV for surveillance and revised clinical staging and immunological classification of HIV-related disease in adults and children (2007).

[25] WHO 2008. Worldwide prevalence of anaemia 1993-2005. WHO Global database on anaemia (2008).

[26] Partec Gmbh. Protocol for CD4+ T-cell counting with the Partec CD4 easy Count Kit. (Partec Code No. 05-8401). Partec Gmbh, Otto-Hahn-Str. 32, D-48161 Munster, Germany (2006).

[27] Obonyo C.O., Shah S.N., Smith E., Bloland P.B., Slutsker L. and Hamel M. The impact of HIVinfection on response to antimalaria treatment: Preliminary results of an antimalarial efficacy trial in HIV-infected and HIV-uninfected adults in Siaya District, Kenya. Global forum for Health Research, Forum 8, Mexico City (2004).

[28] Cheesbrough M. Parasitological tests in District Laboratory Practice in Tropical Countries. Part 1.Cambridge Low-Price Editions, Cambridge University Press. Pp191 - 214 (2005).

[29] Snounou G., Zhu X., Siripoon N., Jarra W., Thaithong S., Brown K.N., Viriyakosol S. Biased distribution of msp-1and, msp-2 allelic variants in Plasmodium falciparum populations in Thailand. Trans R Soc Trop Med Hyg, 93:369-374 (1999). 
[30] Sanyaolu A.O., Fagbenro-Beyioku A.F., Oyibo W.A., Badaru O.S., Onyeabor O.S. and Nnaemeka C.I. Malaria and HIV co-infection and their effect on haemoglobin levels from three healthcare institutions in Lagos, southwest Nigeria. African Health Sciences, 13(2): 295 - 300 (2013).

[31] Marchiafava E. and Bignami A. On summer-autumn malarial fevers. London: The New Syndenham Society. (translated from the Italian first ed. by J Harry Thompson) (1894)

[32] Deaderick W.H. (1909). A practical study of malaria. Philadelphia: WB Saunders.

[33] Rzepczyk C.M., Stamatiou S., Anderson K., et al Experimental human Plasmodium falciparum infections: longitudinal analysis of lymphocyte responses with particular reference to gamma delta T cells. Scand J Immunol, 43:219-27 (1996).

[34] Church L.W., Le T.P., Bryan J.P., et al. Clinical manifestations of Plasmodium falciparum malaria experimentally induced by mosquito challenge. J Infect Dis, 175:915-20. (1997)

[35] Markell E.K., John D.T. and Krotoski W.A. Medical parasitology. Philadelphia: WB Saunders (1999).

[36] Ladhani S., Lowe B., Cole A.O., Kowuondo K. and Newton C.R. Changes in white blood cells and platelets in children with falciparum malaria: relationship to disease outcome. $\mathrm{Br} \mathrm{J}$ Haematol, 119:839-47 (2002).

[37] Scadden D.T., Zon L.I. and Groopman J.E. Pathophysiology and management of HIV-associated hematologic disorders. Blood, 74:1455-1463 (1989).

[38] Whitworth J., Morgan D., Quigley M., Smith A, Mayanja B., Eotu H., Omoding N., Okongo M., Malamba S. and Ojwiya A. Effect of HIV-1 and increasing immunosuppression on malaria parasitaemia and clinical episodes in adults in rural Uganda: a cohort study. Lancet, 356: 1051 - 1056 (2000).

[39] Rutto E.K., Nyagol J., Oyugi J.., Ndege S., Onyango N., Obala A., Simiyu C.J., Boor G., Cheriro W.C., Otsyula B. and Estambale B. Effects of HIV-1 infection on malaria parasitemia in milo sub-location, western Kenya. BMC Research Notes, 8:303 (2015).

[40] Ngoundou-Landji J., Nwuba R.I., Anumudu C.I., Odaibo A.B., Maya W.D.M., Awobode H.O., Okafor C.M., Morenikeji O.A., Asinobi A., Nwagwu M., Holder A.A. and Ntoumi F. Fine specificity of anti-MSP119antibodies and multiplicity of Plasmodium falciparum Merozoite Surface Protein 1 types in individuals in Nigeria with sub-microscopic infection. Malaria Journal, 9:287 (2010).

[41] Atroosh W.M., Al-Mekhlafi H.M., Mahdy M.A.K., Saif-Ali R., Al-Mekhlafi A.M. and Surin J. Genetic diversity of Plasmodium falciparum isolates from Pahang, Malaysia based on MSP-1 and MSP-2 genes. Parasites \& Vectors, 4:233 (2011).

[42] Mwingira F., Nkwengulila G., Schoepflin S., Sumari D., Beck HP., Snounou G., Felger I., Olliaro P. and Mugittu K. Plasmodium falciparum msp-1, msp-2 and glurp allele frequency and diversity in sub-Saharan Africa. Malaria Journal, 10:79 (2011).

[43] Amodu O.K., Olaniyan S.A. and Omotade O.O. Changes in Plasmodium Falciparum Population Dynamics in Two Populations at Different Time Periods in Ibadan, Southwest Nigeria. Afr. J. Biomed. Res., Vol.18: 17- 22 (2015).

[44] Kang J.M., Moon S.U., Kim J.Y., Cho S.H., Lin K., Sohn W.M., Kim T.S. and Na B.K. Genetic polymorphism of merozoite surface protein-1 and merozoite surface protein-2 in Plasmodium falciparum field isolates from Myanmar. Malar J, 9:131 (2010)

[45] Legrand E., Volney B., Lavergne A., Tournegros C., Florent L., Accrombessi D., Guillotte M., Puijalon O.M. and Esterre P. Molecular analysis of two local falciparum malaria outbreaks on the French Guiana coast confirms the msp1B-K1/varD genotype association with severe malaria. Malar J, 4:26 (2005).

[46] Hassan, A., Babadoko, A.A., Mamman, A.I. and Ahmed, S.A. Zidovudine-induced pure red cell aplasia presenting after 4 years of therapy. AIDS. 19:2046-7 (2009).

[47] Belperio, P.S. and Rhew D.C. Prevalence and outcomes of anaemia in individuals with human immunodeficiency virus: a systematic review of the literature. Am J Med. 116 (suppl7A): 27S43S (2004). 